\title{
Transformation of the Capital Market Stability Model under the Influence of the Financial Globalization
}

\author{
Rustam R. Akhmetov ${ }^{1}$ \\ ${ }^{1}$ Kazan Federal University, Institute of Management, Economics and Finance, Kazan, Russia \\ Correspondence: Rustam R. Akhmetov, Kazan Federal University, Institute of Management, Economics and \\ Finance, Kazan, 420008, Russia.
}

Received: December 27, 2014

Accepted: February 19, 2015 Online Published: April 30, 2015

doi:10.5539/ass.v11n1 1p123

URL: http://dx.doi.org/10.5539/ass.v11n11p123

\begin{abstract}
In the course of economic globalization a process of formation of the united financial market has evolved. Integratedness of different sectors of financial market into its global form is largely stipulated by development of financial innovations and of new financial instruments. Subjacent and timeless nature of modern financial transactions leads to blurring of distinction between money and capital markets. The united market means a gradual merge of financial risks and increase of volumes and unpredictability of aggregate risk in the result of synergetic effect contained in the nature of financial market as of a nonlinear dynamical system. Serious influence on stability of financial market has a behavioral psychology of its participants that is connected with reflexivity specific to financial capital. Financial market can be described only by nonlinear stochastic equations. In this article we made the efforts to set the parameters for such a model. Basing on non-stability of a global financial market and under influence of globalization factors it was concluded that it is necessary to check the hypotheses on formation of a financial cycle apart from general business cycle.
\end{abstract}

Keywords: financial globalization, financial cycle, financial market stability, nonlinear dynamical systems, securitization

\section{Introduction}

Consequences of economic crisis, problems of financial state of several states including leading economics of the world, issues of Russia's entry to the World Trade Organization (WTO) and discussions connected therewith - all of it can be regarded as a reflection of world economics internationalization and globalization process. We single out two methodological principles of global financial market analysis: first - structural and functional, second - institutional (Akhmetov, 2011). The first principle is connected with study of functions of money and capital, their changes in a modern world, dynamics of offer and demand on money and capital. Structural analysis relates to structure and dynamics of financial markets. Institutional principle binds market analysis primarily with organization of the market and functioning of its institutions. Issues of institutional development of a financial market are highly important for study and specification of modern processes in the sphere of finances.

From this point of view globalization process is a factor that unites in itself both methodological approaches. The central component of world economic globalization is financial globalization. In the result of financial globalization the capital became much more mobile having moved all over the world to the most attractive and profitable capabilities of application. Nature of operations of the global market participants with diversification of assets and liabilities according to states and regions, availability of wide network of representative offices, branches and subsidiary organizations abroad so far does not allow identifying them only with the country of national identity. Financial globalization has strengthened influence of international markets on performance of credit and borrowing operations by residents of different countries that lead to growth of international network of financial institutions and corporations increase of business participation falling on foreign countries and to fundamental changes in their systems of organization of financial flows management.

Along with the benefits financial openness and integration are increasing risk. Consequence in advance of the development of financial globalization is that capital flows are poorly coordinated with the flow of technology. That's why globalization does not actually provide full of technological exchange (Mosey, 2002). This contradicts the traditional economic paradigm, according to which globalization, accompanied by the 
liberalization of capital movements, should lead to a reduction in systemic risk. In fact, the global financial crisis 2007-2009 refuted this assertion. Neither diversification of bank portfolios nor the policy of the monetary authorities do not reduce banking risks, but rather strengthens them (Laeven \& Valencia, 2008).

Financial sphere pretends to be an absolute leader of economic globalization. The notion of globalization is often understood as a wide distribution and spread primarily of financial institutions and financial markets. Availability of financial markets any participants in the globe leads to the generation of a new financial world without borders, where the power of speculators and managers of the cash funds outshine the power of central banks and politicians.

According to Independent Strategy specialists about $40 \%$ of global manufacturing of industrial products, $60 \%$ of global value product, $70-90 \%$ of world trade and international finances are influenced by globalization. This proves the fact that financial sphere is much more affected by globalization processes much more than other economic spheres (Roche, Manca, \& Mckee, 2006).

In our opinion all diversity of specific features and forms financial globalization can be generalized by four groups:

- General financial forms proving rapid growth of financial markets;

- Organizational features reflecting transformation processes in content and structure of financial institutions;

- Management forms connected with the change of role of governments and international organizations;

- Informational and technological forms and ideological features specifying development and growth of information technologies and changes in the sphere of social consciousness (Akhmetov, 2009).

\section{Methodology of Financial Markets Globalization Analysis}

We would like to consider each of the form closer in order to determine the degree of their influence on stability of financial markets.

1. General financial features of globalization can be more vividly shown in correlation of real and financial sectors. Financial sector part in global manufacturing of products and services has grown and dominates both by its part and by its economic significance. If in 1975 the proportion of international operations with shares and stocks with GDP in developed countries was not more than 5\%, by the beginning of XXI century it has grown up to $700 \%$. What caused such a growth?

One of the main reasons was disinflation that is the process of deceleration of price growth rates. Thus, if the average income of 10-year's bonds in the markets of the OECD countries for 25 years (1981-2006) has amounted $3.7 \%$, inflation during the same period has amounted only to1.7\%.Deceleration of inflation rates during the last quarter of the century is stipulated by several fundamental factors. First reason was a strengthened purposeful anti-inflation policy of governments and of central banks of the states. Monetary powers of developed countries have transformed low inflation into prior purpose of their activity. Governments of the states - OECD members have limited interference into economics and state expenses ("Reaganomics" and "Thatcherism" in 1980-s). The result was decreasing of budgetary expenses and diminution of the need to financing budgetary deficits including at the expense of increase of money supply.

Secondly, in the result of globalization international trade barriers have been lowered, and a flow of correspondingly cheap goods has swept into markets of highly developed countries primarily from Asia (India, China etc.). The prices began to decrease due to of competitiveness of the manufacturers.

The third factor of disinflation was a serious increase of efficiency of manufacturing and trading of private companies all over the world. Development of new technologies, including internet service in the sphere of trading and of information exchange and also increase of management quality within the companies made a significant contribution to it.

Table 1. Growth of global financial assets

\begin{tabular}{lccccc}
\hline & 1980 & 1990 & 2000 & 2005 & 2010 \\
\hline $\begin{array}{c}\text { Financial assets (money, shares, bonds) of countries of the Seven as the } \\
\text { interest from GDP }\end{array}$ & 150 & 210 & 370 & 400 & 530 \\
\hline
\end{tabular}


Stable deceleration of inflation rates in a long-term perspective has gradually lead to the fact that real interest rates in Organization for Economic Cooperation and Development countries nowadays have become much lower than their long-term values. During disinflation period financial assets were increasing much quicker than material assets and GDP.

In general financial sense globalization is also characterized by the fact that rapid change of international financial development brought new directions and forms of internationalization of manufacturing, trade and finances that in its turn leads to convergence of capitals of many countries in different forms and modifications (Figure 1).

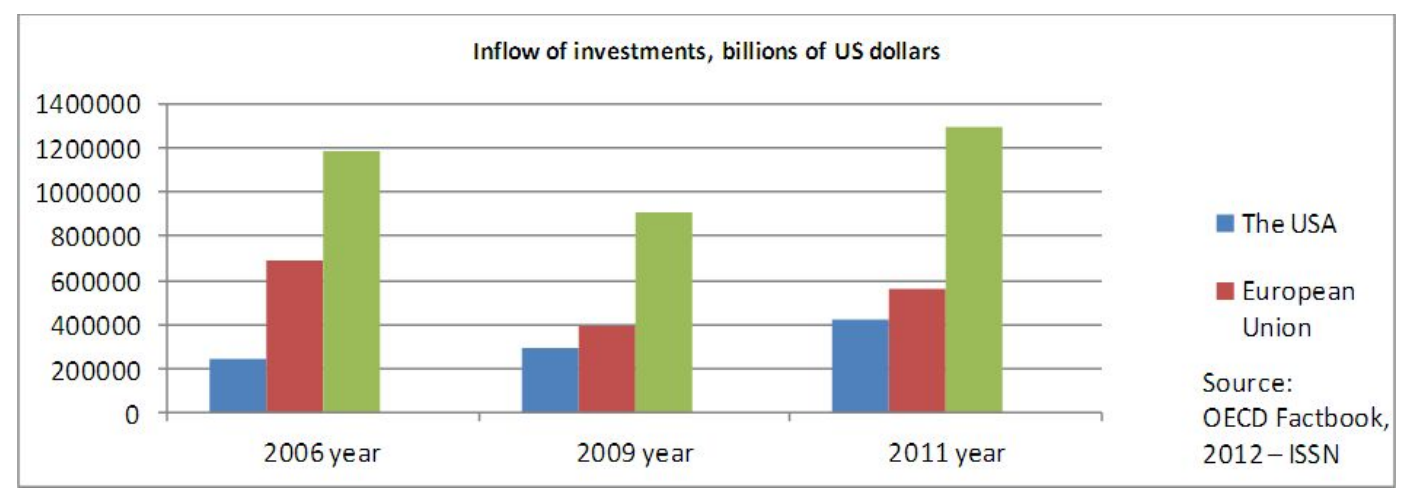

Figure 1. Foreign direct investments in OECD countries

One of such modifications has become synchronization of business cycle development during the last several years. Opinion about world cycle desynchronization that has appeared before crisis of 2007-09 has been based on the fact of general long-term recovery in global economics during 16 years - from 1992 to 2007. Data specified on graphics (Figure 2) shows dynamics of industrial manufacturing in four leading OECD countries has been changing synchronically during the last 20 years. Unemployment situation has not been so clear: European labor market at times of its recovery has been significantly different from American and Japanese markets - that is most noticeable on the example of Germany. In the 1990s, the peak of unemployment in the US and the UK came in the beginning of the decade (1993 and 1994 he. Respectively), in Germany and Japan - at the end of it (1997 and 2000. Respectively). In the 2000s, the differences in the movement rate of unemployment remained: if the US and the UK came in the post-crisis peak effects (2010 and 2011), then in Germany at this time of unemployment even decreased, and the peak came in the middle of the decade (2004-2006 ).

There is evidence that the integration of trade and industry processes have a stronger impact on the finance sphere than consumption (Kose, Prasad, \& Terrones, 2003).

2. Organization features of financial globalization, reflecting internal processes in the sphere of different sectors of financial market and transformations in the content and structure of financial institutions. Organizational peculiarities of globalization processes in 1990-2000 were expressed by:

- Convergence of activities of banks with non-banking financial institutions (funds, insurance organizations and etc.);

- Securitization of assets and erasing of distinction between monetary and capital markets;

- Decrease of the role of transnational companies and transnational banks (TNC and TNB) in global economics.

On the one hand, there was blurring of the banks from traditional financial institutions into new more diversified structures. On the other hand, non-banking financial organizations have so much infiltrated into activity of banks at the pick of deregulation of 80 -s that in deprived the banks from the leading role in big business financing. Broker firms offer their clients cash management services, transactions control service, insurance products sale. Insurance agents begin to register sale of securities, insurance companies sale shares of mutual funds. Banks also trade with mutual funds, offering in addition to it discount broker services.

Appearance of new financial institutions reflecting features of different sectors of the market became the result of convergence of financial institutions. The brightest and the most stable example of it is the securitization process that is a transformation of its financial assets into securities. 
The other important organizational feature of globalization is a process of gradual blurring of the distinction between monetary and capital markets. Securitization lays the basis for it. Let us consider securitizing mortgages emission as the example. Upon issuing them financial institution can save payment for initial mortgages. This allows them to take two advantages: firstly, they do a comparatively easy transfer of the interest rate and credit risks to the investor. Secondly, in fact issuing a new mortgage on the basis of a previous one the issuer procures a some kind of recycling of the capital. Bank or other financial institution uses a mortgage capital acquired in the result of emission in order to perform a further mortgage loan, and to reflect as income assets obtained from it (Veale, 1987).

Emission of individual mortgages is connected with the increased risk. Firstly, because they require larger primary investments: most individual mortgages have a high minimal cost. That itself increases nominal size of risk capital. Secondly, such securities based on derivative instruments have a more complex credit risk evaluation. Investor often lack of time, resources and expert capacities for evaluation of the property being mortgaged, employment verification, credit checks and other things necessary for adequate and complete evaluation of a credit risk of individual securitizing mortgage. Thirdly, there is no a stable market on such mortgages that indirectly causes liquidity problems.

For these reasons liquid market of individual mortgages has not been developed until institutes operating them began securitizing their mortgage portfolios. For the first glance it allowed to significantly simplify analysis and trading of these securities. As for mortgages securitization process widely began when financial institutions (banks etc.) began to sale their mortgages to more specialized sophisticated finance brokers. This concerns not only MBS but also a whole range of other similar instruments (participating certificates, collateralized mortgage obligations, adjustable rate mortgages, collateralized bond obligations, credit default swaps), that in its turn caused a rush of global growth of derivatives and risks connected therewith.

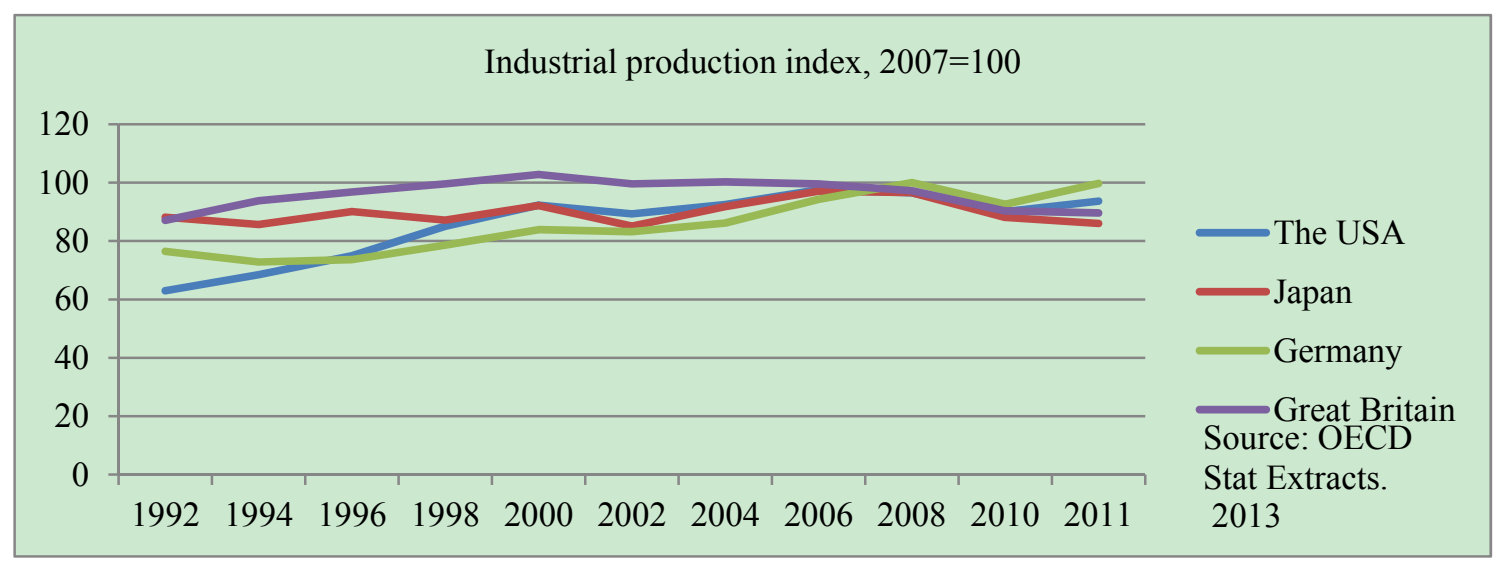

Figure 2. Dynamics of industrial manufacturing of developed countries

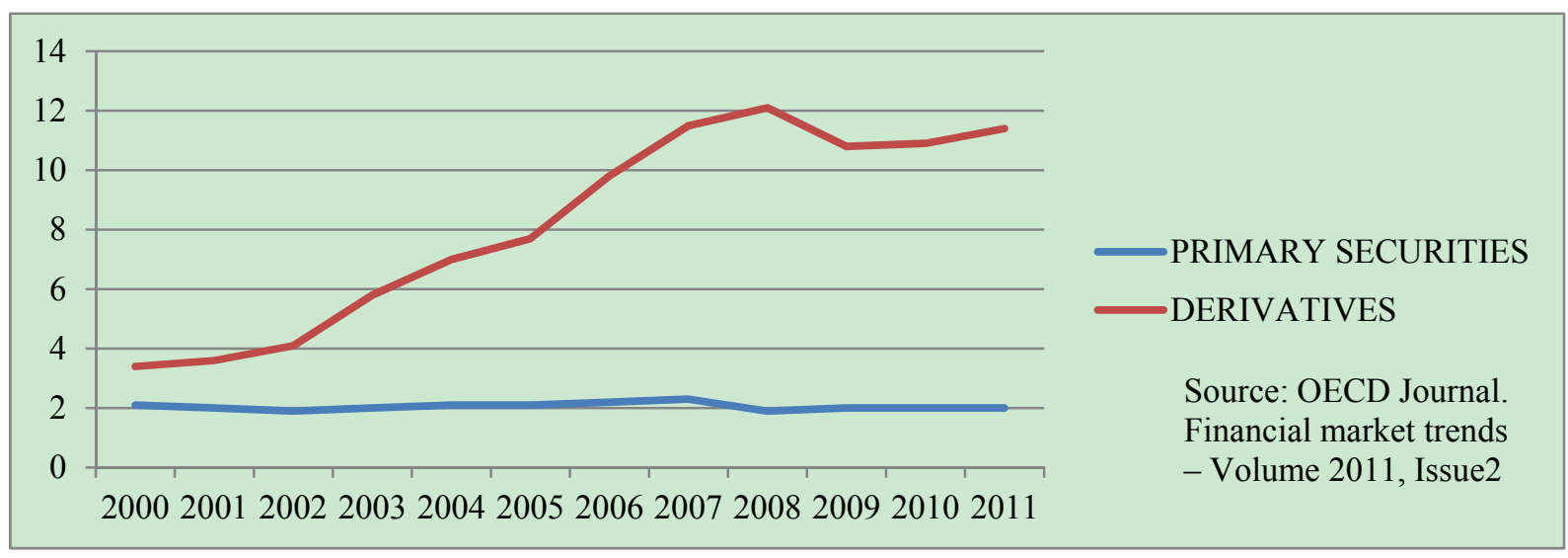

Figure 3. Dynamics of world volume of primary securities and nominal cost of derivatives 
Figure 3 shows growth of primary securities (bonds and equities) and bank assets compares with off-market derivatives. The growth rate of derivatives volume was almost five times bigger than the primary securities during the period from 1998 to 2011. If in the middle of 1998 volume of global derivatives amounted to 2.5-3 worlds' GDP, on the eve of the crisis, in June 2008, it has been 12-13 times bigger than worlds' GDP. At the same time primary securities volume during the same period has remained stable that has been approximately two times bigger than GDP.

Earlier banks have explained mountains of derivatives by the fact that they were necessary to control risks and also for innovation and efficiency in economics (Blundell-Wignall, 2011). Some of derivatives performed social tasks connected with hedging of business risks. It should be noted the use of derivatives for tax arbitration (interest rates swaps for the differences tax treatment of products). Credit-Default Swaps (CDS) have been widely used for arbitrary regulation in order to minimize the required bank capital.

However, according to many researchers during the last decade this social use of derivatives has been minimal. Their general increasing trend is reported to make the decade the worse one from the point of view of financial risks from the times of the Great Depression. So called social function of derivatives allowed leverage to rise and this way to extremely increase the risk (Blundell-Wignall \& Atkinson, 2011). The important fact in this relation is the continuous increase of a gap between revolving derivatives and primary securities. Due to the fact that primary securities lay the foundation for and largely ensure security of derivatives market, the said divergent trend between the volumes of them shows increasing overuse of the same security (rehypothecation), that multiplies joint risk through bank system.

3. Managerial features of globalization are connected with the change of roles of governments and international organizations. The current level of global market mechanisms is far from perfect and yet can not perform a function of a global regulator, because speculative methods of actions of its members is a feature both of the market in general and of actors taking part therein. Difficulties in national and international regulation of global processes occur.

The important factor of globalization is that modern means of informatization allow to radically change the whole system of management from small firms up to global economic and financial system. Therefore, the role and significance of the state and of international organization in regulation of global financial system will be changed. Participation of both of them in affecting financial markets shifts to sector-specific, but stricter supervision and control (Sax, 1994).

4. The other important feature of globalization is informational and ideological component. This feature is so important that some authors play the main emphasis on it. In our opinion informational component of globalization can be generalized by following factors. First of all, it is a growth of requirements to the market and its participants on revealing of information. Secondly, psychological effect of financial innovations, that is appearance and implementation of new instruments and technologies in financial markets, is an important aspect. The third form is informational inequality formed in the result of technological revolution.

Limited rationalizing and computing problems of information processing lead to substitution of a complete analysis of the whole information by precedent or analogue solution, by use of a priori or herdlike behavior. Rapid growth of information, its continuous updating and improvement is accompanied by a dynamic increase of bulk of excessive, repeating, inaccurate information - appearance of so called noises. Popularity of the idea of irrational control in modern management can be served as the example of practical activity in terms of informational inequity. The Companies act by trial and error not in a manner of maximal rational reckoning.

\section{Results}

Development of main forms of financial globalization had a great impact on financial market stability. How the above mentioned tendencies can reflect on global financial market development rates? What effect do these tendencies have on financial market stability: do they contribute to its growth or strengthen destabilization?

We assume that financial markets correspond to nonlinear dynamical system. This statement is based on the following hypotheses. First of all, we agree that change of prices in financial markets happen in a random way. It means that subsequent changes of prices do not depend on each other. This statement has been proved by facts (L. Bachelier, M. Kendall, E. Fama). Bachelier argued that the expectation of the speculator is zero, and the process of price changes $\mathrm{S}=\left(S_{t}\right) t \geq 0$ is a random process. Exploring the time series of prices with a time interval $\Delta \mathrm{t}$, he noticed that the difference $\left(S_{t}-S_{t-\Delta}\right)$ has zero mean and fluctuation order $\sqrt{\Delta}$. These properties have a random walk: 


$$
S_{t}=S_{0}+\sum_{\Delta}^{k \Delta} x_{\Delta}
$$

where $x_{\Delta}$ - identically distributed independent variables, which can take two values, $\pm \sigma \sqrt{\Delta}$ with equal probabilities (1/2). Limit as aspiration $\Delta \rightarrow 0$ leads to a random process based on Brownian (Wiener) motion.

M. Kendall claimed not the prices themselves and their logarithms are subject to a random walk, that is, if

$$
z_{n}=\ln \frac{S_{n}}{S_{n-1}}
$$

then $S_{n}=S_{0} e^{z_{n}}, \mathrm{n} \geq 1$, where $Z_{n}$ - the sum of independent random variables $z_{1}, \ldots z_{n}$.

Secondly, we assume that reflexivity is specific to global financial capital. As G. Soros has shown there is a bilateral connection between current decisions and future events in stock market. Forthcoming quotes depend on current expectations of investors just as prices themselves influence on expectations. For the reason of reflexivity in the market the balance is nearly to be unreachable (Soros, 1988).

Thirdly, the leading role in financial markets plays not rational behavior of the investors (that in our opinion does not exist at all), but a psychological factor of market members. The market is a correlation of psychologies of its participants lead by their individual motives that mostly do not have much common with reasonability. This gives a reason to think that change of market prices and market behavior in general can not be described by classical financial models with a sufficient degree of authenticity. Here works the mechanism of the reflexivity: prices influence on expectations, expectations form prices. In crucial moments during crises actions of market laws of competitiveness and pricing are being overlapped with panic, rumors, perverted expectations. It is difficult to predict investor's behavior as well as financial rates during such periods.

Such behavior is studied in theory of behavioral finance and in modern models of nonlinear systems and stochastic theories of crises and cycles. Nonlinearity brings numerous developmental pathways that are refracted in bifurcation points in an unpredictable manner. Nonlinear systems mathematically can be described with nonlinear differential equations binding range of the unknown function at a point and range of its derivatives of different orders at the same point:

$$
F\left(t, x, x^{1}, x^{11}, \ldots x^{(n)}\right)=0,
$$

where $\mathrm{x}=\mathrm{x}(\mathrm{t})$ is an unknown function depending on time variable $\mathrm{t}$.

Provided that because market dynamics is of occasional and largely discrete nature, it can be subject primarily to stochastic differential equations that include occasional processes. Such equations have complex appearance and solution because solving is also a stochastic process. For this system of first-order stochastic differential equation in a form of Langevin equation are used:

$$
x_{i}=\frac{d x_{i}}{d t}=f_{i}(x)+\sum_{m=1}^{n} g_{i}^{m}(x) \eta_{m}(t),
$$

where $x=\left\{x_{i} \mid 1 \leq i \leq k\right\}$ is a set of unknowns, $f_{i}$ and $g_{i}$ are arbitrary functions, and $\eta_{m}$ is random function from time. Economic sense of stochastic differential equations for financial market can described as follows: financial assets price is a result of balance of profitability of the company-issuer and market risk functions on the one hand and functions of investors' expectations on the other hand.

In order to assign a dynamical system it is necessary to describe its phase field that is a variety of possible states at a fixed point of time. Moreover, it is necessary to assign a variety of timepoints $t$ and (most importantly) the rule describing movement of points of the phase field during the time.

Let us assume that phase field $\mathrm{X}$ is a variety of all possible states in periods of time $\mathrm{T}$, including variety $\mathrm{t}$. If we know information appearance (processing) speed $a_{i}(x)$, path described by point $x_{0} \in X$ will be a solution to differential equation $\frac{d x}{d t}=\alpha(x)(5)$

$$
\text { Equations system }\left\{\begin{array}{c}
\frac{d x}{d t}=\alpha \\
\frac{d a x}{d t}=-\beta x
\end{array}\right.
$$

establishes a continuous-time dynamical system (harmonic oscillator). Such system can shape various fluctuating motions, in this case time fluctuations of market prices towards shares depending on expectations of investors. 
However, having any assignment of dynamical system it is not always possible to find it and describe its pathways in an explicit form. That's why usually more simple issues about general behavior of the system are being considered.

Here appears the biggest difficulty formulating the financial market regularities: phase field of this system cannot be accurately assigned by a set of numbers or end variety of the field in a multidimensional space, because in this case we deal with nonlinear system. The internal feature of nonlinear systems is a synergetic effect, dynamical chaos, lack of predictable pathways of development and stability.

\section{Discussion}

Financial stability is an integral part of the overall economic stability. We define economic sustainability as the ability of an object (the economic system) to resist cyclic phenomena in the economy and the impact of external factors beyond the system.

John Downes and Jordan Goodman distinguish several types of stabilization: the currency, economic, market trading (Kirshin, 2014 May). The meaning of all treatments reduced to price and current market stability. According to the so-called "crisis" financial stability definition of stability is regarded as state of the financial system or the opposite unstable market, i.e. which shall not involve destabilizing the situation bearing a threat the financial crisis (Downes \& Goodman, 1995).

In this context, mention should be made of the theory of financial stability H. P. Minsky. According to it the stock market passively reflects estimates of future returns on investments made by real investors. The very same financial system although does not effect on decision-making in the real sector, but because of their uncertainty makes the economy inherently unstable (Lakshina \& Chekmareva, 2005). According to Minsky asset valuation is not objective process, as is done in the face of uncertainty. This essentially means recognizing emotions by integral part of market behavior. According to Minsky, the boom periods caused to a tendency to reduce expectations of risks and waiting for the value of assets. This causes growth of lending and, consequently, increased vulnerability to risk. Liquidity problems can cause a crisis of insolvency through a "domino effect" (Minsky, 1983).

\section{Conclusion}

Let us return to main forms of financial market globalization. Within the framework of the reviewed model they can lead to double-side effect. Being the elements uniting and converging markets, they will contribute to their stability. At the same time being elements that unreasonably expand and complexify markets, they are factors increasing their risks and destabilization potential. In financial world are becoming less multiple repeated situations and events basing on which statistical regularities can be determined. Quantitative optimization allows answering the question which part of the risk can be really measured, but does not help to answer the question what is the real total risk value?

Financial market supervisions pay too little attention to systemic risks arising from leverage and potential implications of rapidly increasing financial globalization for the transmission of shocks across the borders (Dow, 2010). In modern structure of financial market we can talk about immanent instability having not only momentary but in a cycle nature. Cyclicity of financial markets does not have a direct material basis, but is proved by a number of preconditions. Among those we rate:

- Capacity of blowing financial and credit bubbles in the result of growth of nonproductive sector of economy;

- Mass distribution of the latest financial instruments and technologies of increased risks;

- Procycle behavior of some leading and coincident indicators in financial market;

- Deregulation of financial markets within the framework of global economy and national economics of the leading countries.

Analysis of the said interrelations and assessment of financial cycle formation possibility is a further stage of financial market stability factors research.

\section{References}

Akhmetov, R. (2009). Development of financial markets within modern cycle. Finance and credit, 27(363), $51-55$.

Akhmetov, R. (2011). Methodological approaches to analysis of financial market conditions. Intelligence, Innovations, Investments, 1, 104-109.

Blundell-Wignall, A. (2011). Solving the Financial and Sovereign Debt Crises in Europe. OECD Journal: 
Financial market trends, 2, 1-23.

Blundell-Wignall, A., \& Atkinson, P. (2011). Global SIFIs, Derivatives and Financial Stability. OECD Journal, Financial Market Trends, 1. http://dx.doi.org/10.1787/fmt-2011-5kg55qw0qsbv

Dow, S. C. (2010). The Psychology of Financial Markets: Keynes, Minsky and Emotional Finance. Voprosy Economiki, 1, 199-213. http://dx.doi.org/10.4337/9781849807098.00019

Downes, J., \& Goodman, J. F. (1995). Dictionary of Finance and Investment Terms (p. 628). New-York: Barron's.

Fama, E. (1981). Stock Returns, Real Activity, Inflation and Money. American Economic Review, 71(4), 545-565.

Kirshin, I. A. (2014, May). Ecological restrictions of modern economic growth. Studies on Russian Economic Development, 25(3), 276-282. http://dx.doi.org/10.1134/S1075700714030046

Kirshin, I. A., \& Kuzminov, S. V. (2014). Evaluation method development for regional economies competitiveness. Mediterranean Journal of Social Sciences, 5(18), 159-164. http://dx.doi.org/10.5901/mjss. 2014.v5n18p159

Kose, M., Prasad, E., \& Terrones, M. (2003). How does globalization affect the synchronization of business cycle? IMF Working Paper, January, International Monetary Fund.

Laeven, L., \& Valencia, F. (2008). Systemic Banking Crises: A New Database. IMF Working Paper, Nov. $\mathrm{WP} / 08 / 224$.

Lakshina, O., \& Chekmareva, H. (2005). Financial stability analysis: practice and methodology. Money and Credit, 10, 25.

Minsky, H. P. (1983). The Financial Instability Hypothesis: an Interpretation of Keynes and an Alternative to "Standard Theory". In J. C. Wood (Ed.), Critical Assessments (pp. 282-292).

Mosey, G. (2002). Globalization and regionalization processes in the world economy. Economist, 9, 24-28.

Roche, D., Manca, G., \& Mckee, B. (2006). New Monetarism. Independent Strategy. Retrieved October 13, 2011, from http://www.instrategy.com/books.php

Sax, J. (1994). Beautiful Renaissance. The Economist, 1, 27-28.

Soros, G. (1988). The Alchemy of Finance. Retrieved December 25, 2013, from http://www.polbu.ru

Veale, St. (Ed.). (1987). Stocks, bonds, options, futures. Investments and their markets (p. 332). New-York Institute of Finance, Simon \& Schuster Co.

\section{Copyrights}

Copyright for this article is retained by the author(s), with first publication rights granted to the journal.

This is an open-access article distributed under the terms and conditions of the Creative Commons Attribution license (http://creativecommons.org/licenses/by/3.0/). 